\title{
PEDO-TRANSFER FUNCTIONS FOR PREDICTING TOTAL SOIL NITROGEN IN DIFFERENT LAND USE TYPES UNDER SOME TROPICAL ENVIRONMENTS
}

\author{
S. A. Mesele* And G. A. Ajiboye \\ (S. A. M.: International Institute of Tropical Agriculture (IITA), Ibadan, Nigeria; G. A. A.: \\ Department of Soil Science and Land Management, \\ Federal University of Agriculture Abeokuta Nigeria.). \\ *Corresponding author's email: ayodelemesele@hotmail.com
}

\begin{abstract}
Nitrogen pedo-transfer functions were developed for different land use types, soil depths and agro-ecologies across eight states in Nigeria. The results showed that total nitrogen had a good relationship with the soil organic carbon; therefore, the functions developed were based on the relationship between organic carbon and total nitrogen as other soil parameters $(\mathrm{pH}$, and particle size distribution) had little contribution and no significant correlation $(p>0.05)$ with total nitrogen. Correlation and forward stepwise regression and Kendall's Coefficient Concordance were used to fit and validate the developed model with datasets other than those used for the model formulation. The $\mathrm{R}^{2}$ of the best fitted regression models varied from 0.77 to 0.85 . We obtained a generalized fitted model $\left(\mathrm{TN}=0.0736^{*} \mathrm{OC}, \mathrm{R}^{2}=0.83\right)$ which is independent of the agroecology and the land use types. Significant fitted models were also obtained for the arable farms $\left(\mathrm{TN}=0.08 * \mathrm{OC}, \mathrm{R}^{2}=0.85\right)$ and the plantation farms $(\mathrm{TN}=$ $0.0698^{*} \mathrm{OC}, \mathrm{R}^{2}=0.83$ ). It was discovered that variations in agro-ecology, land use, and soil depth did not significantly affect the model performance.
\end{abstract}

Keywords: soil organic matter, modelling, soil property, agroecology, Nigeria

\section{Introduction}

Since the beginning of the 19th century, there have been several attempts to predict some complex soil properties from some easily observable or analyzable properties using empirical models known as pedotransfer functions (PTFs) (Van Genuchten, 1980; Krogh et al., 2000; Ayoubi \& Karami, 2019). Among such PTFs is estimation of total soil nitrogen using easily determinable soil physical and chemical properties such as soil texture, $\mathrm{pH}$ and total organic carbon (Wosten et al., 2001; Pachepsky \& Rawls, 2004).
Most of the PTFs on total soil nitrogen and other PTFs such as hydraulic functions, cation exchange capacity was developed for temperate or arid soils using data sets derived from temperate or arid regions (Minasny et al., 1999; Tamari et al. 1996; Benke et al. 2020). There are several evidences that indicated that some of the empirical models developed from temperate regions might not function properly under tropical conditions (Hodnett et al., 1995). Evidence from the work of Tomasellaet al. (2000) indicated that a PTF developed for Brazilian soil using data sets (soil physical 
and chemical properties) obtained from Brazil produced better results than the adoption of PFT developed from a temperate soil. They concluded that there might have been functional differences between temperate and tropical soils caused by some factors other than texture.

The observed deviation between the temperate and tropical environment could have resulted from variation in such properties as the clay mineralogy, soil fractal composition, $\mathrm{pH}$, soil drainage and some anthropogenic conditions (Evangelou \&Marsi, 2003; Rashidi \& Seilsepour, 2008; Cordeiro et al 2020). As such PTFs for predicting total soil nitrogen might not be universally applicable but may have to be developed directly for the soils of interest due to variation in the aforementioned soil properties.

Among the macronutrients required for optimal performance of most crops, $(\mathrm{N})$ is regarded as the most important in the tropical environment (Michopoulos et al., 2008). However, $\mathrm{N}$ is one of the most limiting nutrients in soils (Vitousek \&Farrington, 1997). As such, $\mathrm{N}$ is one of the routinely analysed soil chemical properties necessary for predicting fertilizer requirements for the production of most crops, especially cereals, root and tuber crops. However, the routine digestion and distillation method of Kjeldahl is time consuming and involves the use of concentrated acids which release acid fumes that are not environmentally friendly. Also, the cost of automated analyser for total nitrogen is expensive and beyond the reach of most routine soil analytical laboratories. In most of the third world countries, where the cost of energy is high and sometimes irregular in supply, rapid determination of total soil nitrogen is sometimes non attainable or very expensive. Thus, there have been several attempts in estimating the total soil nitrogen accurately from other easily measurable soil parameters like soil organic carbon, texture and drainage conditions.

Glendining et al. (2011) developed PTFs for estimating total soil nitrogen up to the global scale. The model was: $\mathrm{TN}=0.0232$ $+0.0250 * \mathrm{C}-0.000534 * \mathrm{D}+0.521 * \mathrm{G}+\mathrm{a}(\mathrm{T})$, for $\mathrm{C}<10$, and $\mathrm{TN}=0.269+0.0449^{*} \mathrm{C}-$ $0.00575^{*} \mathrm{D}-0.157 * \mathrm{G}+\mathrm{b}(\mathrm{T})$, for $\mathrm{C} \geq 10 \%$, where $\mathrm{C}$ is $\% \mathrm{SOC}, \mathrm{D}$ is the degrees from the equator, $\mathrm{G}$ is a soil group factor defined as (C/Median $\mathrm{C}: \mathrm{N}$ ratio of soil group), $\mathrm{T}$ is a factor based on soil texture classes (1,2 or 3), depending on clay and sand content and (a) takes the value $0.0,0.0228$ or 0.0296 when $\mathrm{T}$ is 1,2 or 3 , respectively, and similarly $\mathrm{b}$ takes one of the values $0.0,0.328$ or 0.440 , respectively and $\mathrm{TN}$ is the total soil nitrogen. We found this model to be cumbersome, a bit unrealistic and impractical to use by local extension workers in Nigeria. Another model based on the relationship between total soil $\mathrm{N}$ with soil organic carbon was also developed by Rashidi \& Seilsepour (2009) but has not been verified for the Nigerian soils. This paper therefore provides models that predict the total soil $\mathrm{N}$ using easily measured parameters. It also verified one of the existing models with data from several soil samples collected at different land use types and agro-ecologies across Nigeria.

\section{Experimental}

Two major agro-ecologies in Nigeria were studied (rainforest and derived savanna). The soils used for this study were collected from eight (Cross River, Osun, Ondo, Edo, Ogun, Kogi, Kwara \& Oyo) States of Nigeria covering two major ecological zones (Derived Savanna and Rainforest). Also, the soils were 
collected from both surface $(0-30 \mathrm{~cm})$ and pedogenic horizons of profile pits (up to 140 $-180 \mathrm{~cm}$ depth). In addition, the land uses selected include plantation crop land (Cocoa plantation, Gmelina plantation, Plantain plantation, Oil palm plantation) and arable crop lands (Cassava, maize and rice). This was done to increase the variability in the soil types (textural composition, $\mathrm{pH}, \mathrm{OC}$ and total soil $\mathrm{N}$ contents), thus making the soils to be representative of the major soil classes that can be encountered in these ecological regions.

The Walkley Black wet oxidation method was used in the determination of the total organic carbon content of the soil (Walkley \& Black, 1934), while the Kjedhal digestion and distillation procedure as outlined by Soil Survey Staff (1996), was used for the determination of the total nitrogen of the soil samples. Soil physical properties such as bulk density, consistency, texture and pore sizes were determined using standard protocols as documented in Soil Survey Staff(1996). SoilpH was measured using soil to water ratio 1:2 with the aid of a pH meter (Mclean, 1965). Particle size distribution analysis was carried out using the hydrometer method (Bouyoucous, 1962). Total exchangeable acidity was determined by titrimetric method. Available phosphorus in the soils was extracted using Bray-1 solution (Bray \& Kurtz, 1945), and the concentration of $\mathrm{P}$ in the extracts was determined colorimetrically on spectrophotometer at 882 $\mathrm{nm}$ using the blue molybdate method. The soil exchangeable bases were extracted with ammonium acetate at $\mathrm{pH} 7$ (NH4OAc $\mathrm{pH} 7$; Van Reeuwijk, 2002) and read with atomic absorption spectrophotometer (AAS). Base saturation was calculated as the percentage of the sum of the exchangeable bases divided by the CEC. Micronutrients were extracted in soil samples with $0.1 \mathrm{M}$ hydrochloric acid (1:6) and the extracts were read using AAS.

Statistical analysis and model development Data were analysed with Genstat version 9 using correlation and multiple linear regression models at $5 \%$ probability level. The minimum data points for each of the model is 120 (n $=120$ ). The stepwise regression analyses that were carried out between the total soil nitrogen and the other soil parameters like \% organic carbon (OC), $\mathrm{pH}$, sand, silt and clay, the fitted models were tested with the one developed by Rashidi \& Seilsepour (2009) using different data that were not used in the model formulation. Validation of the predicted models was carried out using Kendall's coefficient concordance.

Kendall's coefficient of concordance is a nonparametric statistic. It is a normalization of the statistic of the Friedman test, and can be used for assessing agreement among raters. Kendall's W ranges from 0 (no agreement) to 1 (complete agreement). Kendall's $\boldsymbol{W}$ is defined as follows.

Assume there are $m$ raters rating $k$ subjects in rank order from 1 to $k$. Let $r_{i j}=$ the rating rater $j$ gives to subject $i$. For each subject $i$, let $R_{i}=\sum_{j=1}^{m} T_{i j}$.

let $\vec{R}$ be the mean of the $R_{i}$ and let $R$ be the squared deviation, i.e.

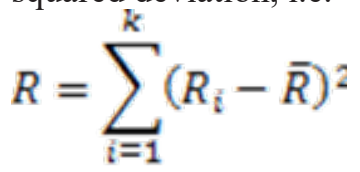


Now define Kendall's $\boldsymbol{W}$ by

$W=\frac{12 R}{m^{2}\left(k^{3}-k\right)}$

Observation: For each rater $j$

$\sum_{i=1}^{k} r_{i j}=1+2+\cdots+k=\frac{k(k+1)}{2}$

and so the mean of the $R_{i}$ can be expressed as $\bar{R}=\frac{1}{k} \sum_{i=1}^{k} R_{i}=\frac{1}{k} \sum_{i=1}^{k} \sum_{j=1}^{m} r_{i j}=\frac{1}{k} \sum_{j=1}^{m} \sum_{i=1}^{k} r_{i j}=\frac{1}{k} \sum_{j=1}^{m} \frac{k(k+1)}{2}=\frac{m(k+1)}{2}$

Observation: By algebra, an alternative formulation for $W$ is

$W=\frac{12 S^{2}}{m^{2}\left(k^{3}-k\right)}-\frac{3(k+1)}{k-1}$

Where,

$S^{2}=\sum_{i=1}^{k} R_{i}^{2}$

If all the raters are in complete agreement

(i.e., they give the same ratings to each of the subjects) then

$S^{2}=\sum_{i=1}^{k} R_{i}^{2}=\sum_{i=1}^{k}(m j)^{2}=m^{2} \sum_{i=1}^{k} j^{2}$

But

$\sum_{i=1}^{k} j^{2}=\frac{k(k+1)(2 k+1)}{6}$

and so
$W=\frac{12 S^{2}}{m^{2}\left(k^{3}-k\right)}-\frac{3(k+1)}{k-1}=\frac{12 m^{2} k(k+1)(2 k+1)}{6 m^{2} k(k-1)(k+1)}-\frac{3(k+1)}{k-1}=\frac{2(2 k+1)}{k-1}-\frac{3(k+1)}{k-1}=1$

If all the $R_{i}$ are the same (i.e., the raters are in complete agreement), then as we have seen, $W$ $=0$. In fact, it is always the case that $0 \leq W \leq$ 1. If $W=0$ then there is no agreement among the raters.

Morgan's rule of model validation was further employed to validate the newly predicted values using the calculated ratio of the actual to the predicted values (Morgan, 2005).

\section{Results and discussion}

General characteristics of the soils of the study area

The average characteristics of the soils taken from three states is presented in Table 1 and typify the profiles from which soil samples were collected under Cocoa, Gmelina, Plantain and Oil palm plantations within the rainforest and savanna agroecologies of Nigeria.

In term of colour, the soils were grouped into two because of the contrasting colour hue in the surface and subsurface horizons. The first category of soils had colour hue of $10 \mathrm{YR}$ in the surface horizons with colour values that ranged from three to five while the colour chroma ranged from one to six. Thus, the surface horizons of these soils had colour variation between yellowish brown and dark gray while the subsurface horizons had different shades of colour ranging in colour hue from 2.5Y, 10YR to 7.5YR. The subsurface colour ranged from white $(2.5 \mathrm{Y}$ $8 / 2$ ) to reddish yellow (7.5YR 6/6). 
TABLE 1

Physico-chemical characteristics of the modal profiles of the study area.

\begin{tabular}{|c|c|c|c|c|c|c|c|c|}
\hline \multicolumn{5}{|c|}{ Forest ecology / Plantation } & \multicolumn{4}{|c|}{ Savanna ecology / Arable land } \\
\hline Depth & $0-34$ & $34-81$ & $81-123$ & $123-180$ & $0-18$ & $18-42$ & $42-76$ & $76-140$ \\
\hline Sand $(\%)$ & 73.15 & 55.48 & 47.70 & 48.48 & 80.00 & 78.00 & 60.00 & 60.00 \\
\hline Silt (\%) & 7.93 & 7.63 & 6.98 & 7.08 & 9.00 & 7.00 & 7.00 & 19.00 \\
\hline Clay $(\%)$ & 18.93 & 36.90 & 45.33 & 44.45 & 11.00 & 15.00 & 33.00 & 21.00 \\
\hline Texture & SL & $\mathrm{SC}$ & $\mathrm{SC}$ & $\mathrm{SC}$ & SL & SL & SCL & SCL \\
\hline Ks & 8.46 & 14.41 & 3.05 & 2.27 & 132.99 & 134.83 & 233.89 & 134.83 \\
\hline $\mathrm{BD}$ & 1.15 & 1.28 & 1.36 & 1.35 & 2.08 & 2.17 & 2.26 & 2.16 \\
\hline Pore & 46.03 & 43.81 & 42.68 & 45.13 & 35.00 & 32.00 & 32.00 & 31.00 \\
\hline pHwater & 4.93 & 4.81 & 4.99 & 5.03 & 6.70 & 6.20 & 6.20 & 6.20 \\
\hline $\mathrm{pH}(\mathrm{CaCl} 2)$ & 4.16 & 3.98 & 4.05 & 3.98 & 4.80 & 3.80 & 4.00 & 4.70 \\
\hline OC (\%) & 1.67 & 0.74 & 0.46 & 0.32 & 0.68 & 0.34 & 0.33 & 0.33 \\
\hline $\mathrm{TN}(\%)$ & 0.14 & 0.08 & 0.06 & 0.05 & 0.04 & 0.02 & 0.03 & 0.01 \\
\hline $\mathrm{C} / \mathrm{N}$ & 11.05 & 9.29 & 7.50 & 5.92 & 16.19 & 20.00 & 9.71 & 33.00 \\
\hline TEA $\left(\mathrm{cmol} \mathrm{kg}^{-1}\right)$ & 0.30 & 0.40 & 0.59 & 0.70 & 0.00 & 0.00 & 0.00 & 0.00 \\
\hline $\mathrm{Mg}\left(\mathrm{cmol} \mathrm{kg}^{-1}\right)$ & 0.50 & 0.28 & 0.45 & 0.43 & 0.49 & 0.24 & 1.13 & 0.66 \\
\hline $\mathrm{Ca}\left(\mathrm{cmol} \mathrm{kg}^{-1}\right)$ & 3.30 & 0.98 & 1.03 & 0.91 & 1.67 & 0.40 & 0.91 & 0.43 \\
\hline $\mathrm{K}\left(\mathrm{cmol} \mathrm{kg}^{-1}\right)$ & 0.13 & 0.09 & 0.10 & 0.16 & 0.17 & 0.06 & 0.17 & 0.15 \\
\hline $\mathrm{Na}\left(\mathrm{cmol} \mathrm{kg}^{-1}\right)$ & 0.23 & 0.26 & 0.33 & 0.35 & 0.03 & 0.05 & 0.09 & 0.04 \\
\hline $\begin{array}{l}\text { ECEC } \\
\left(\mathrm{cmol} \mathrm{kg}^{-1}\right)\end{array}$ & 4.47 & 2.01 & 2.50 & 2.55 & 2.36 & 0.74 & 2.29 & 1.28 \\
\hline BS $(\%)$ & 86.63 & 75.64 & 73.39 & 69.54 & 100.00 & 100.00 & 100.00 & 100.00 \\
\hline $\begin{array}{l}\text { Avail-P (mg } \\
\mathrm{kg}^{-1} \text { ) }\end{array}$ & 3.80 & 9.42 & 9.84 & 2.93 & 2.47 & 2.06 & 2.67 & 2.47 \\
\hline $\mathrm{Fe}\left(\mathrm{mg} \mathrm{kg}^{-1}\right)$ & 171.31 & 164.65 & 122.22 & 91.57 & 71.86 & 83.86 & 58.53 & 77.20 \\
\hline $\operatorname{Mn}\left(\mathrm{mg} \mathrm{kg}^{-1}\right)$ & 259.30 & 236.76 & 209.29 & 191.04 & 175.40 & 179.39 & 156.21 & 131.24 \\
\hline $\mathrm{Cu}\left(\mathrm{mg} \mathrm{kg}^{-1}\right)$ & 4.34 & 3.99 & 2.91 & 2.09 & 1.46 & 1.46 & 1.71 & 0.96 \\
\hline $\mathrm{Zn}\left(\mathrm{mg} \mathrm{kg}^{-1}\right)$ & 0.36 & 0.30 & 0.11 & 0.07 & 2.31 & 0.63 & 0.78 & 12.09 \\
\hline
\end{tabular}

$\mathrm{SL}=$ sandy loam, $\mathrm{SC}=$ sandy clay, $\mathrm{SCL}=$ sandy clay loam, $\mathrm{Ks}=$ saturated hydraulic conductivity, bulk density in $\mathrm{Mg} / \mathrm{m}^{3}, \mathrm{TEA}=$ total exchanchable acidity, $\mathrm{BS}=$ base saturation

Most of the soils in this group had few - many, very fine - medium, diffuse - sharp and faint - prominent mottles in some of the subsurface horizons. The mottles colour ranged from $10 \mathrm{YR}$ to $10 \mathrm{R}$ with colour value that ranged from four to six while the chroma ranged from four to eight.
The soils in the second group had different colour matrix with colour hue of 5YR in the surface horizons and colour values that ranged from three to four while the colour chroma ranged from four to six. These soils had surface colour that ranged from dark reddish 
brown (5YR 3/3) to yellowish red (5YR 4/6). The subsurface horizons of the soils in this group had colour hue of $5 \mathrm{YR}$, colour value that ranged from three to four and colour chroma which ranged from four to six. As such, the subsurface colour ranged from dark reddish brown to yellowish red. The soils had structures that varied from fine-sub-angular-blocky (fsbk) in the surface horizon to coarse-sub angular-blocky (csbk) in the sub soil. The consistency of the soils ranged from very friable in the surface to firm in the subsurface.

In term of chemical properties, the soil reaction ranged from extremely acid to moderately acid (4.20 - 6.65 in distilled water) and from extremely acid to very strongly acid $(3.45-4.90$ in $\mathrm{KCl})$. The organic carbon content of the soil ranged from $3.59 \%$ in the surface horizon to $0.04 \%$ in the subsurface horizon. Generally, the organic carbon content of the soil decreased expectedly with increase in soil depth. Like in most Nigerian soils, the total nitrogen content of the soils was very low $(<0.10 \%)$ in the subsurface horizons but slightly higher $(0.11-0.267 \%)$ in the surface horizons. The carbon nitrogen $(\mathrm{C}: \mathrm{N})$ ratio of the soils ranged from1.39 to13.47 and generally decreased with increase in soil depth. The available phosphorus content of the soils (Bray -1$)$ ranged from very low $(1.28 \mathrm{mg}$ $\left.\mathrm{kg}^{-1}\right)$ to high $\left(21.88 \mathrm{mg} \mathrm{kg}^{-1}\right)$. The total exchangeable acidity $\left(\mathrm{H}^{+}+\mathrm{Al}^{3+}\right)$ of the soil were low - high and ranged from 0.10 to $2.20 \mathrm{cmol}$ $\mathrm{kg}^{-1}$. The exchange sites of the soils were dominated by $\mathrm{Ca}^{2+}$ which had values that ranged from $0.05 \mathrm{cmol} \mathrm{kg}^{-1}$ in the subsurface horizons to $9.48 \mathrm{cmol} \mathrm{kg}^{-1}$ in the surface horizons. The values of $\mathrm{Mg}^{2+}$ in the soils also ranged from 0.08 to $0.76 \mathrm{cmol} \mathrm{kg}^{-1}$ while the values of $\mathrm{K}^{+}$ in the soils ranged from 0.07 to $0.16 \mathrm{cmol} \mathrm{kg}^{-}$ 1. The $\mathrm{Na}^{+}$ranged from 0.21 to $0.57 \mathrm{cmol} \mathrm{kg}^{-1}$ and the effective cation exchange capacity
(ECEC) ranged from 1.67 to $10.75 \mathrm{cmol} \mathrm{kg}^{-1}$. The exchangeable bases $(\mathrm{Ca}, \mathrm{Mg}, \mathrm{K}$ and $\mathrm{Na}$ ) and ECEC of these soils were very low. The available micronutrients ( $\mathrm{Fe}, \mathrm{Mn}, \mathrm{Cu}$ and $\mathrm{B}$ ), on the other hand, were very high. The values of iron content of the soils ranged from 12.30 to $413.64 \mathrm{mg} \mathrm{kg}^{-1}$ while the manganese $(\mathrm{Mn})$ content ranged from 0.49 to $531.48 \mathrm{mg} \mathrm{kg}^{-1}$. These two elements ( $\mathrm{Fe}$ and $\mathrm{Mn}$ ) had very high values which were considered as toxic in some of the pedons. However, the copper $(\mathrm{Cu})$ content of the soils was moderate to high and ranged from 0.02 to $16.94 \mathrm{mg} \mathrm{kg}^{-1}$ and the values were generally highest in the surface horizons. The zinc ( $\mathrm{Zn})$ content of the soils was very low and ranged from 0.05 to $1.54 \mathrm{mg} \mathrm{kg}^{-1}$.

The soils of the derived savanna used for arable cropping were fairly deep $(>70 \mathrm{~cm}$ in depth) and had texture which were predominantly loamy sand (LS) in the surface horizons with sandy clay loam/sandy clay (SCL/ SC) subsurface horizons. The soils had colour that ranged from dark reddish brown (5YR 3/2 on the surface to dark red (2.5YR 3/6) in the subsurface horizons. At some points within profiles, mottling occurred at depths usually below $75 \mathrm{~cm}$. The mottle which is indicative of imperfect drainage at such depth during certain period of the year were many in abundance, yellowish brown (10 YR 6/8), medium - coarse in size, prominent and distinct. Generally, the soils were well drained and had moderately formed medium subangular blocky structure and firm to very firm consistency. In addition, some of the soils (those under the forest agroecology) had iron - manganese concretion (plinthite) at some depths which in most cases was below $70 \mathrm{~cm}$ depth.

The soils of the derived savanna ecology had moderate to high saturated hydraulic conductivity $(\mathrm{Ks}=59.62-132.99$ $\mathrm{cm} \mathrm{h}^{-1}$ ) in the first horizon of the profile. 
However, the Ks decreased drastically in the last horizons indicating a highly reduced infiltration rate with increasing soil depth. This phenomenon is caused by the clayey nature of the soil subsurface horizon. The bulk density of this soil type ranged from $1.91 \mathrm{~g} \mathrm{~cm}^{-3}$ on the surface to $2.26 \mathrm{~g} \mathrm{~cm}^{-3}$ in the sub surface horizon. The gravelly nature of this soil is probably the cause of the high bulk densities observed in this soil type. In term of chemical properties, the organic carbon content of the soils of this mapping unit were low and ranged from $0.33 \%$ to $0.68 \%$. In the same vein, the phosphorus and potassium contents of the soils were very low. While the soils had phosphorus content that ranged from $2.06 \mathrm{mg}$ $\mathrm{kg}^{-1}$ to $2.88 \mathrm{mg} \mathrm{kg}^{-1}$, the potassium content of the soils ranged from $0.06 \mathrm{cmol} \mathrm{kg}^{-1}$ to 0.17 cmol $\mathrm{kg}^{-1}$. Similar to most savanna land in Nigeria, the total nitrogen $(\mathrm{N})$ content of the soil of this soil type was lower than the critical requirement for most arable crop grown within this ecological zone $(\mathrm{TN}=0.15 \%)$. The values of the $\mathrm{N}$ content of the soil ranged from $0.010 \%$ to $0.047 \%$. The $\mathrm{pH}$ of the soils in distilled water ranged from slightly acid (6.1) to neutral (6.7) while the effective cation exchange capacity (ECEC) was also very low and ranged from $0.74 \mathrm{cmol} \mathrm{kg}^{-1}$ to $3.84 \mathrm{cmol}$ $\mathrm{kg}^{-1}$. However, the micronutrients content of the soils was all high. While the values of available copper $(\mathrm{Cu})$ which ranged from 0.96 to 3.20 and zinc $(\mathrm{Zn})$ which ranged from $0.63 \mathrm{mg} \mathrm{kg}^{-1}$ to $12.09 \mathrm{mg} \mathrm{kg}^{-1}$ were high but not toxic, the concentration of iron $(\mathrm{Fe})$ and manganese (Mn) in the soils were excessively high and could be toxic. While the soil content Fe ranged from $58.53 \mathrm{mg} \mathrm{kg}^{-1}$ to $142.52 \mathrm{mg}$ $\mathrm{kg}^{-1}$, the Mn content of the soils ranged from $131.24 \mathrm{mg} \mathrm{kg}^{-1}$ to $230.55 \mathrm{mg} \mathrm{kg}^{-1}$.

\section{Carbon - Nitrogen regression analysis}

It was observed that only $\% \mathrm{OC}$ had significant correlation with total nitrogen (TN). The multiple linear forward stepwise regression model indicated that $\% \mathrm{OC}$ alone could significantly explain about $80 \%$ observed variations in $\%$ $\mathrm{TN}$ under all the various categories considered. We therefore subsequently limit our models to fit the relationship between TN and OC.

Kendall's Coefficient Concordance test showed that the two models behaved in a similar pattern (Fig.1). The results indicated that the developed model had a validation ratio that ranged from 0.6 to 1.4 which falls within the acceptance range of 0.5 to 2.0 . 


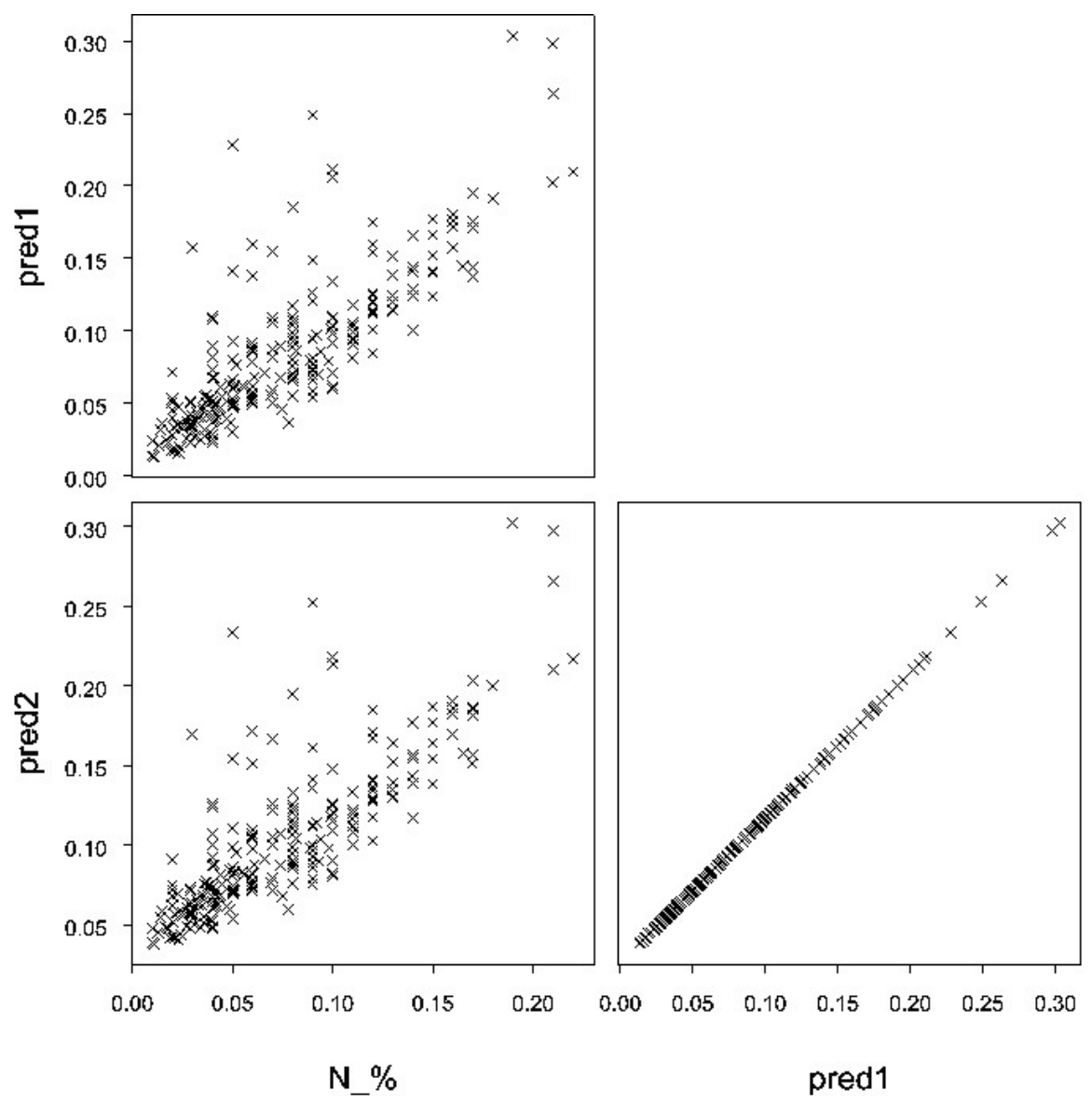

Fig. 1: Coefficient concordance test of the developed model with an existing model and \%TN.

NB: Pred 1 = the newly generalized models Pred $2=$ Existing model developed by Rashidi and Seilsepour (2009).

Pedo-transfer functions for Total $N$ under different land use systems

The result shows that total nitrogen had a linear positive relationship with the soil organic carbon under the two land use types. On the arable farm (Table 2, Fig. 2), a unit increase in the soil organic carbon led to an increase of 0.08 in the percentage total nitrogen while a unit increase in percent organic carbon led to an increase of 0.07 in percentage total nitrogen on the plantation farms (Fig.3). Both relationships have strong coefficients of determination which imply that total nitrogen could be confidently predicted from the soil organic matter. The best fitted model for the arable farm was $\mathrm{TN}=0.08 * \mathrm{OC}, \mathrm{R}^{2}=0.85$ while that of plantation was $\mathrm{TN}=0.0698^{*} \mathrm{OC}$, $\mathrm{R}^{2}=0.83$ (Table 2). 
TABLE 2

Summary of the various models developed.

\begin{tabular}{lll}
\hline Category & Model & $\mathbf{R}^{2}$ \\
Topsoil & $\mathrm{TN}=0.0734 * \mathrm{OC}$ & 0.78 \\
Subsoil & $\mathrm{TN}=0.0742 * \mathrm{OC}$ & 0.77 \\
Arable land & $\mathrm{TN}=0.08 * \mathrm{OC}$ & 0.85 \\
$\begin{array}{l}\text { Plantation land } \\
\text { Rainforest }\end{array}$ & $\mathrm{TN}=0.0698^{*} \mathrm{OC}$ & 0.83 \\
$\begin{array}{l}\text { ecology } \\
\text { Savanna ecology }\end{array}$ & $\mathrm{TN}=0.0736 * \mathrm{OC}$ & 0.83 \\
$\begin{array}{l}\text { Generalised } \\
\text { model }\end{array}$ & $\mathrm{TN}=0.0736^{*} \mathrm{OC}$ & 0.80 \\
\hline
\end{tabular}

$\mathrm{TN}=$ total soil nitrogen; $\mathrm{OC}=$ organic carbon
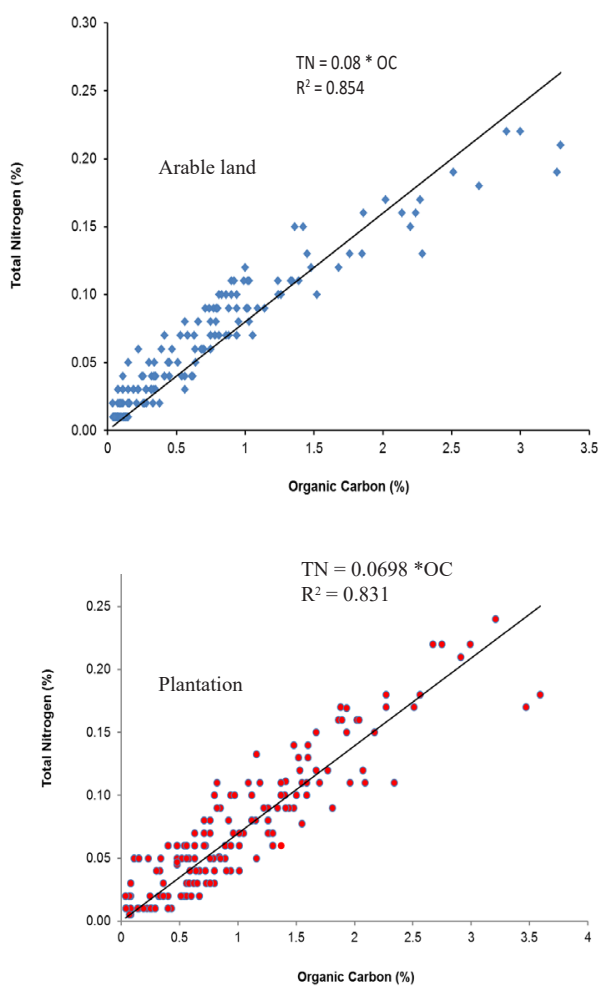

Fig. 2: Total $\mathrm{N}$ and $\mathrm{OC}$ relationship under land use.
Pedo-transfer functions for Total $N$ under different agro-ecologies

Agro-ecological characteristics defined soil properties. Total $\mathrm{N}$ and organic matter had positive linear relationships (Fig. 3). A unit increase in organic carbon led to an increase in total $\mathrm{N}$ by a factor of 0.07 under the two agro-ecologies. The best fitted model for the rainforest agroecology was $\mathrm{TN}=0.0736^{*} \mathrm{OC}$, $\mathrm{R}^{2}=0.83$ while that of savanna was $\mathrm{TN}=$ $0.0736^{*} \mathrm{OC}, \mathrm{R}^{2}=0.80$. The high coefficients of determination of the linear functions suggest that total soil $\mathrm{N}$ could be predicted using any of the functions (Table 2).
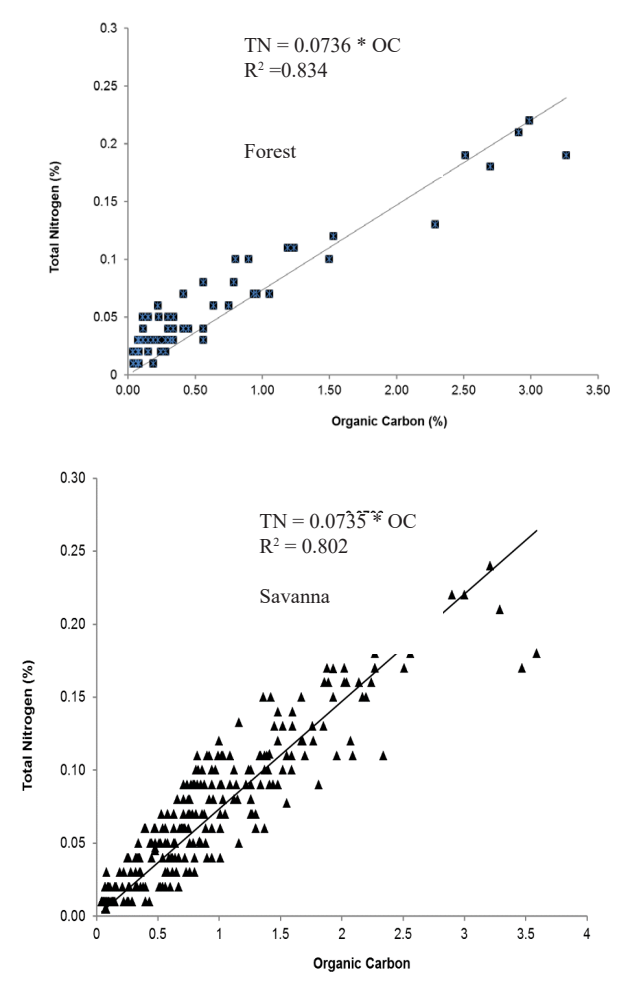

Fig. 3: Total $\mathrm{N}$ and $\mathrm{OC}$ relationship based on agroecology. 
Total Soil N pedo-transfer functions for

different soil depths

Soil properties vary across the soil profile with the topsoil usually richer in nutrients and organic carbon. It was envisaged that the use of a single pedo-transfer function might not be appropriate for different soil depths particularly topsoil and the subsoil. The relationship between total soil $\mathrm{N}$ and organic carbon follows the same trend as it was under different agro-ecologies (Fig. 4). The result indicated that the best fit models for topsoil and the subsoil are $\mathrm{TN}=0.0734^{*} \mathrm{OC}, \mathrm{R}^{2}=0.78$ and $\mathrm{TN}=0.0742 * \mathrm{OC}, \mathrm{R}^{2}=0.77$ respectively.

All the data used for different categories were pooled and fitted to obtain a generalized model irrespective of agro-ecology, land use and soil depths (Fig. 5). The regression equation obtained was $\mathrm{TN}=0.0736^{*} \mathrm{OC}$. $\mathrm{R}^{2}=0.83$. Further analyses using either soil textural compositions or $\mathrm{pH}$ in combination with organic matter did not produce a better result. This underscores the strong association between soil organic carbon and total N, thus any management practice that affects the soil organic carbon would therefore affect the total soil N (Obalum et al., 2012). Practices that enhance soil organic carbon build-up should therefore be promoted to increase the amount of nitrogen available to the crops particularly on smallholder farms.
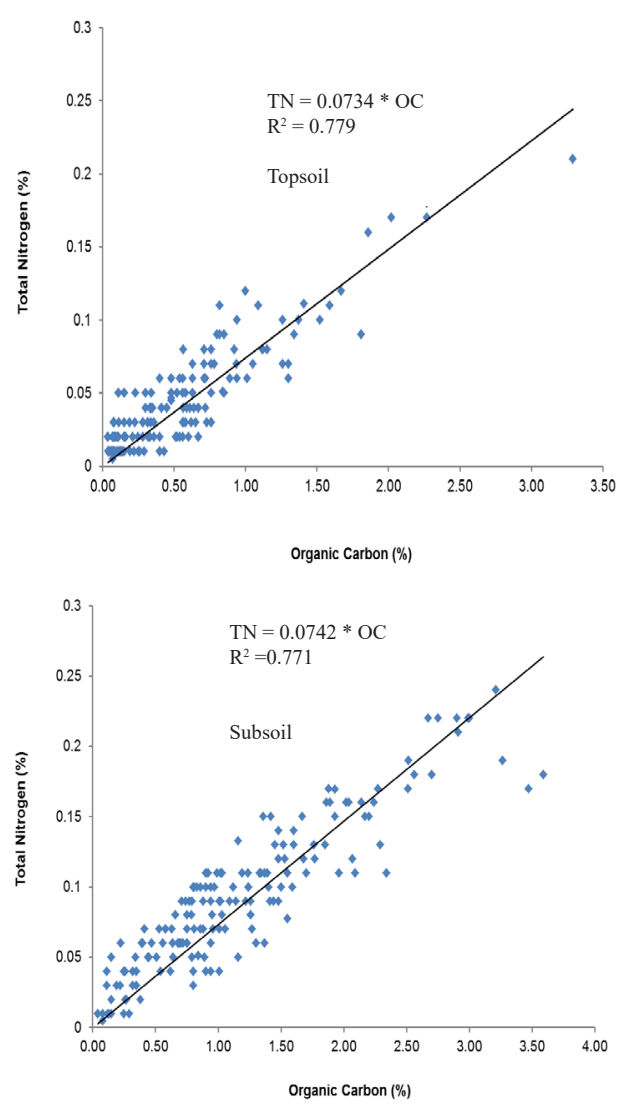

Fig. 4: Total N and OC relationship based on soil depth

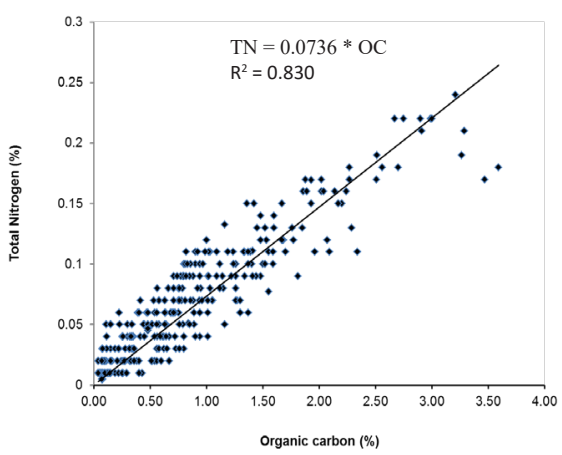

Fig. 5: Pedotransfer function for all soil types 


\section{Conclusion}

Nitrogen pedo-transfer functions were developed for different land use types, soil depths and agro-ecologies across eight states in Nigeria. The results showed that the total nitrogen content of the soil could be accurately predicted from the soil organic carbon contents. However, it was observed that the increase in the prediction accuracy obtained by developing different PTF for each agro-ecological zone, land use type and soil depth was not significantly different from those obtained in the generalized model. The models we developed were simple, straight-forward and easy to use and could be applied without modification for forest and savanna agroecological zones.

\section{References}

Ayoubi, S. \& KARAmi, M. (2019) Pedotransfer functions for predicting heavy metalin natural soils using magnetic measures and soil properties. Journal of Geochemical Exploration 197, 212 - 219.

Benke, K. K., Norng, S., Robinson, N. J., ChiA, K., Rees, D. B. \& Hopley, J. (2020) Development of pedotransfer functions by machine learning for prediction of soil electrical conductivity and organic carbon content. Geoderma 366, 114 - 210.

Bouyoucous, G. J. (1962) Hydrometer method improved for making particle size analysis of Soils. Agronomy Journal 54, 464 - 465.

Bray, R. H. \& Kurtz, L. T. (1945) Determination of total, organic and available forms of phosphorus in soils. Soil Science 59 (1), 39 $-46$.

Cordeiro, F. R., Cesário, F. V., Fontana, A., Anjos, L. H. C. D., Canto, A. C. B. D.\& Teixeira, W. G. (2020) Pedotransfer functions: the role of soil chemical properties units' conversion for soil classification. Revista Brasileira de Ciência do Solo 44.
Evangelou, V. P. \& Marsi, M. (2003) Influence of ionic strength on sodium-calcium exchange of two temperate climate soils. Plant Soil 250, $307-313$.

Glendining, M. J., Dailey, A. G., Powlson, D. S., Richter, G. M., Catt, J. A. \& Whitmore, A. P. (2011) Pedotransfer functions for estimating total soil nitrogen up to the global scale. European Journal of Soil Science $\mathbf{6 2}$ (1), $13-22$.

Hodnett, M. G., Pimentel Da Silva, L., Da Rocha, H. R. \& Cruz Senna, R. (1995) Seasonal soil water storage changes beneath central Amazonian rainforest and pasture. Journal of Hydrology 170, 233 - 254.

Krogh, L., Breuning, H. \& Greve, M. H. (2000) Cation exchange capacity pedotransfer function for Danish soils. Soil Plant Science 50, $1-12$.

Kucharik, C. J., Brye, K. R., Norman, J. M., Foley, J. K., Gower, S. T. \& Bundy, L. G. (2001) Measurements and modeling of carbon and nitrogen cycling in agroecosystems of southern Wisconsin: Potential for SOC sequestration during the next 50 years. Ecosystem 4, $237-258$.

MClean, E. O. (1965) Aluminum: In methods of soil analysis (ed. C. A. Black) Agronomic No. 9 Part 2, American Society of Agronomy, Madison, Wisconsin, 978 - 998.

Michopoulos, P., Baloutsos, G. \& Economou, A. (2008) Nitrogen cycling in a mature mountainous beech forest. Silva Fennica 42, $5-17$.

Minasny, B., Mcbratney, A. B. \& Bristow, K. L. (1999) Comparison of different approaches to the development of pedotransfer function for water-retention curves, Geoderma 93 $(3-4), 225$ - 253, doi:10.1016/ S00167061(99)00061-0. 
Morgan, R. P. C. (2005) Soil Erosion and Conservation.3rd Edition. National resource institute, Cranfield University.

Obalum, S. E., Buri, M. M., Nwite, J. C, Hermansah, Watanabe, Y, Igwe, C. A. \& WakATSUKI, T. (2012) Soil DegradationInduced Decline in Productivity of SubSaharan African Soils: The Prospects of Looking Downwards the Lowlands with the Sawah Ecotechnolgy. Journal of Applied and Environmental Soil Science. http:// dx.doi.org/10.1155/2012/673926.

Pachepsky, Y. A. \& Rawls, W. J. (1999) Accuracy and reliability of pedotransfer functions as affected by grouping soils. Soil Science Society of American Journal 63, 1748 1757.

Rashidi, M. \& SeIlsepour, M. (2009) Pedotransfer functions for total nitrogen for calcareous soil in varamin soil using organic carbon. International.journal of Agriculture Biology 11, 89 - 92.

SeILSEPOUR, M. \& Rashidi, M. (2008) Prediction of soil cation exchange capacity based on some soil physical and chemical properties. World Application Science. J. 3, 200 - 205.

SOIL SURVEY STAFF (1996) Soil Survey Laboratory Methods Manual. Soil Survey Investigations Rep. 42. Version 3.0. U.S. Government Print, Washington, DC.
Tamari, S., Wosten, J. H. M. \& Ruiz-Suarez, J. C. (1996) Testing an artificial neural network for predicting soil hydraulic conductivity, Soil Science. Society of American Journal 60 (6), 1732 - 1741.

Van Genuchten, M. T. H. (1980) A closed form equation for predicting the hydraulic conductivity of unsaturated soils.Soil Science.Society of American Journal 44, $892-898$.

VAN ReeuwiJK, L. P. (2002) Procedures for soil analysis, International Soil Reference Information Centre, ISRIC, 6th edition, Wageningen, the Netherlands, 120pp.

Vitousek, P. M. \& FARrington, H. (1997) Nutrient limitation and soil development: experimental test of a biogeochemical theory. Biogeochemistry 37, $63-75$.

Walkley, A. \& Black, I. A. (1934) An Examination of Methods for Determining Soil Organic Matter and a proposed modification of the Chromic acid titration method. Soil Science 37, 29 - 37.

Wösten, J. H. M., Pachepsky, Y. \& Rawls, W. J. (2001) Pedotransfer functions: bridging the gap between available basic soil data and missing soil hydraulic characteristics. Journal of Hydrology 251, 123 - 150.

Received 04 Feb 20; revised 03 Dec 20. 